\title{
Treatment resistant postherpetic neuralgia - new treatments, better outcome
}

\author{
Liliane Godinho, Margarida Anastcio, Ana Sofia Pereira, Maria Conceço Martins, Ana Valentim
}

Liliane Godinho [liliane_godinho@hotmial.com]

Margarida Anastcio [margaridaanastacio@yahoo.com]

Ana Sofia Pereira [anasmbpereira@gmail.com]

Maria Conceço Martins [sagi.martins@gmail.com]

Ana Valentim [anavalentim@sapo.pt]

Affiliation: Centro Hospitalar e Universitário de Coimbra, Praceta Prof. Mota Pinto, 3004-561. Coimbra, Portugal.

Correspondence: Liliane Morais F M Godinho. Rua Jorge Bento 234, 1 Esq, 4450-732 Leça da Palmeira, Coimbra, Portugal.

E-mail: liliane_godinho@hotmail.com; Phone: +351965291201

\section{Abstract}

Postherpetic neuralgia (PHN) is a chronic and painful condition characterized by persistent pain following resolution of a herpes zoster infection. Management of PHN can be challenging as this disorder is difficult to treat and many strategies have been described to reduce such pain. The objective of the treatment of PHN is primarily pain alleviation and improvement of the quality of life. We report a case of a patient with PHN treated with capsaicin patch, after therapeutic failure of other drugs indicated as first and second-line treatment. Side effects of systemic therapy have limited therapeutic compliance and consequent limited pain control. Capsaicin 8\% patch has been shown to be effective, safe, well tolerated without serious adverse reactions in the treatment of neuropathic pain in adults.

Future studies will be necessary to verify the role and cost-effectiveness of capsaicin patch in the management of postherpetic neuropathic pain.

Key words: Postherpetic neuralgia; Pain; Pain, Chronic; Neuropathic pain; Capsaicin patch

Citation: Godinho L, Anastcio M, Pereira AS, Martins MC, Valentim A. Treatment resistant postherpetic neuralgia - new treatments, better outcome. Anaesth. pain intensive care 2020;24(4):453-456.

Received: 11 May 2020, Reviewed: 6 June 2020, Revised: 7 July 2020, Accepted: 25 July 2020

\section{Introduction}

Postherpetic neuralgia (PHN) is a chronic and painful condition characterized by persistent pain following resolution of a herpes zoster (HZ) infection.

Dysfunction of sensory nerves caused by PHN encompasses/consists of spontaneous pain, paresthesia, hyperalgesia, allodynia, and decreased physical activity. Pain is usually described as burning, aching, electrical and/or shock-like in quality. ${ }^{1}$

Epidemiological data show that the risk of $\mathrm{HZ}$ infection and the development of PHN increases with the advancing age. Approximately $20 \%$ of the population is infected with $\mathrm{HZ}$ during their lifetime. ${ }^{2}$
Studies have shown that diabetes mellitus is associated with an increased incidence of some viral infections, ${ }^{3}$ however, there is no evidence proving diabetes is a risk factor for $\mathrm{HZ}$ infections. ${ }^{4}$

When pain persists for more than 180 days after the onset of skin rash, PHN is well established and the possibility of spontaneous pain reduction is reduced. ${ }^{5-}$ 7 Differential diagnosis of pain type is crucial to implement an appropriate treatment.

Management of PHN can be very challenging, as the disorder is difficult to treat and many strategies have been described to manage it. Neuropathic pain is usually associated with the heterogeneity of etiologies, symptoms and underlying mechanisms: it is often refractory to conventional therapies, ${ }^{8}$ based upon the 
use of systemic drugs; hence, tricyclic antidepressants, gabapentin, pregabalin or lidocaine $5 \%$ patches are often recommended as first-line treatments. Secondline treatments generally include tramadol, and in some cases, nortriptyline, imipramine or duloxetine. Strong opioids, other antiepileptics, other antidepressants, cannabinoids, N-methyl-D-aspartate receptor antagonists, memantine, mexiletine and topical low-concentration capsaicin cream are often third-line options, as part of a multimodal approach or as a sole agent. ${ }^{9}$

We report a case of a patient with PHN treated with capsaicin patch, after therapeutic failure of other drugs indicated as first and second-line treatment. Informed consent was obtained before the procedure.

\section{Case report}

A male, 59 years old, factory worker, diagnosed with $\mathrm{HZ}$ infection, reaching the left thoracic and subscapular region, receiving aciclovir $800 \mathrm{mg} \mathrm{4/4}$ hours per os; pregabalin $50 \mathrm{mg}$ per os; diclofenac 50 mg 8/8h per os and inj. cyanocobalamin $0.2 \mathrm{mg}+$ pyridoxine hydrochloride $200 \mathrm{mg}+$ thiamine disulfide $100 \mathrm{mg}$ intramuscularly.

A month later he reported to the emergency department with complaints of persistent pain, despite the above prescribed analgesic therapy. He was discharged with tramadol $50 \mathrm{mg}$ and pregabalin 150 mg twice a day and was referred to the Chronic Pain Unit (CPU). Two months later he was followed up at CPU, reporting continuous and bursting burning pain in the left subscapular thoracic area, with irradiation to the abdomen. On a numerical pain scale, he presented a minimum score of 7 , maximum pain of 10 and usual pain of 9.

Specific questionnaires were used and the results were;

- Douleur Neuropathique Questionnaire 4 (DN4) revealed the presence of a neuropathic component with a DN4 value of 5 (neuropathic component is suggested if $\mathrm{DN} \geq$ 4);

- Hospital Anxiety and Depression Scale Questionnaire (HADS) revealed the presence of significant depression or anxiety, with a value of 14 for the depression component and 13 for the anxiety component (cut off $\geq 8$ );
- $\quad$ Brief Pain Inventory Questionnaire (BPI) revealed high interference with general activity, mood and sleep - component WAW (Walking, Activity and Work) 72.5\%; component REM (Relations with other people, Enjoyment of life and Mood) 60\%; pain component 8.75 ; interference (REM + WAW / 2) $66.25 \%$.

On physical examination, he presented pain localized to the previously infected zone, presenting allodynia and hyperalgesia. Clinical history and physical examination were consistent with the diagnosis of PHN.

He was prescribed pregabalin, tramadol (prolonged release) $150 \mathrm{mg}$ at lunch, domperidone $1 \mathrm{mg} 3$ times daily, tramadol $37.5 \mathrm{mg} /$ paracetamol $325 \mathrm{mg}$ SOS up to 4 times daily and $5 \%$ lidocaine patch.

At follow-up consultations, he reported compliance with therapy and mild symptomatic relief requiring tramadol $37.5 \mathrm{mg} /$ paracetamol $325 \mathrm{mg} 3$ times a day.

One year later, in the follow-up visit, he reported worsening pain associated with non-compliance with oral therapy, due to the drowsiness caused, which was incompatible with his professional situation. The patient only took tramadol $37.5 \mathrm{mg} /$ paracetamol 325 mg SOS and applied the 5\% lidocaine patch. Therapeutic adjustment was performed, and he was prescribed tramadol (prolonged release) $200 \mathrm{mg}$ at bedtime, gabapentin $300 \mathrm{mg} 3$ times a day, duloxetine $60 \mathrm{mg}$ once a day, 5\% lidocaine drug patch and tramadol $75 \mathrm{mg} /$ paracetamol $650 \mathrm{mg}$ SOS, up to 3 times a day. He continued the prescribed therapy with only mild symptomatic relief and was, therefore, proposed for treatment with capsaicin $8 \%$ patch.

He was subjected to the first treatment under left paravertebral block at T7-T8 level, a single shot with levobupivacaine $0.5 \%$ and dexamethasone $8 \mathrm{mg}$. The treatment was uneventful, with complete pain relief. During 3 months he did not need additional therapy but afterward, treatment had to be repeated with capsaicin $8 \%$ patch, due to worsening of the symptoms.

He underwent quarterly treatments with capsaicin patches, always under paravertebral block uneventfully, with full pain relief, and without the need for complementary therapy between treatments. In order to understand the origin of the analgesia, 
paravertebral block was performed only, without administration of capsaicin patch. However, clinical improvement only lasted for 4 days and repeated treatment with capsaicin patch provided symptomatic relief for 3 months.

On his last visit he underwent the fifth treatment, keeping only the capsaicin patch as therapy, and reported a pain relief from score ten to score zero 15 days after the treatment. The Global Change Perception Scale questionnaire revealed a considerable improvement in symptoms, emotions and quality of life since he started this treatment.

\section{Discussion}

The objective of the treatment of PHN is primarily pain alleviation and improvement of the quality of life. ${ }^{10}$ Clinical history with recent $\mathrm{HZ}$ infection has allowed a differential diagnosis of PHN that dictated therapeutic orientation. The underlying cause of PHN is considered to be predominantly neuropathic. ${ }^{11}$

Neuropathic pain is very challenging. Most topical treatments require frequent applications (daily for the lidocaine $5 \%$ patch $)^{12}$. Side effects of systemic therapy have limited therapeutic compliance and consequent limited pain control. Capsaicin $8 \%$ patch has been shown to be effective, safe, well tolerated without serious adverse reactions in the treatment of neuropathic pain in adults. ${ }^{6-8}$

The possibility of discontinuing the systemic medication while maintaining the capsaicin patch alone allowed adequate pain control, permitting our patient to work, and improving the patient's quality of life.

Procedure for using the capsaicin $8 \%$; application of a capsaicin patch requires professional training and is reserved for nurses in chronic pain units ${ }^{11}$. It can be used alone or in combination with other treatments for neuropathic pain. The $14 \mathrm{~cm} \times 20 \mathrm{~cm}\left(280 \mathrm{~cm}^{2}\right)$ patch must cover the zone to be treated and a maximum of four patches can be applied simultaneously for a period of $60 \mathrm{~min}$. However, in order to limit the intense burning sensations induced by capsaicin, an anesthetist's presence was required during the procedure in order to promptly treat any side effects.

\section{Conclusion}

Capsaicin $8 \%$ patch application is an effective remedy of postherpetic neuropathic pain, when other pain management modalities have failed. However, it requires professional training and is reserved for trained nurses in chronic pain units, or even anesthesiologists.

Future studies will be necessary to verify the role and cost-effectiveness of capsaicin patch in the management of postherpetic neuropathic pain, and to identify the patient groups that may benefit the most.

\section{Conflict of interest}

Nil declared by the authors

\section{Authors' contribution}

LG, MA: conduction of the study work and manuscript editing

ASP, MCM: manuscript editing

AV: anesthesiologist working in Chronic Pain Unit, manuscript editing

\section{References}

1. G Gilron I, Watson CP, Cahill CM, Moulin DE. Neuropathic pain: a practical guide for the clinician. CMAJ. 2006 Aug 1;175(3):265-275. [PubMed] DOI: 10.1503/cmaj.060146

2. Suaya JA, Chen SY, Li Q, Burstin SJ, Levin MJ. Incidence of herpes zoster and persistent post-zoster pain in adults with or without diabetes in the United States. Open Forum Infect Dis. 2014 Aug 2;1(2):ofu049. [PubMed] DOI: 10.1093/ofid/ofu049

3. Reilly ML, Schillie SF, Smith E, Poissant T, Vonderwahl CW, Gerard K, et al. Increased risk of acute hepatitis B among adults with diagnosed diabetes mellitus. J Diabetes Sci Technol. 2012;6:858-866. [PubMed] DOI: 10.1177/193229681200600417

4. Heymann AD, Chodick G, Karpati T, Kamer L, Kremer E, Green MS, et al. Diabetes as a risk factor for herpes zoster infection: results of a population-based study in Israel. Infection. 2008:36:226-230. [PubMed] DOI: 10.1007/s15010-007-6347-x

5. Dworkin RH, Gnann JW Jr, Oaklander AL, Raja SN, Schmader KE, Whitley RJ. Diagnosis and assessment of pain associated with herpes zoster and postherpetic neuralgia. J Pain. 2008:9:S37-44. [PubMed] DOI: 10.1016/i.jpain.2007.10.008

6. Jeon YH. Herpes zoster and postherpetic neuralgia: Practical consideration for prevention and treatment. Korean $J$ Pain. 2015;28:177-184. [PubMed] DOI: 10.3344/kjp.2015.28.3.177 
7. Choudhary S, Dhande S, Kharat S, Singh AL. Safety and efficacy of different systemic treatment modalities for acute pain of herpes zoster: a pilot study. Indian Dermatol Online J. 2018 Mar-Apr;9(2):101-104. [PubMed] DOI: 10.4103/idoj.IDOJ_377_16

8. Jay GW, Barkin RL. Neuropathic pain: etiology, pathophysiology, mechanisms, and evaluations. Dis Mon. 2014;60:6-47. [PubMed]

DOI: 10.1016/j.disamonth.2013.12.001

9. Dworkin RH, O'Connor AB, Backonja M, Farrar JT, Finnerup NB, Jensen TS, et al. Pharmacologic management of neuropathic pain: evidence-based recommendations. Pain. 2007;132:237-251. [PubMed] DOI: 10.1016/j.pain.2007.08.033

10. van Wijck AJ, Wallace M,Mekhail N, van Kleef M. Evidencebased interventional pain medicine according to clinical diagnoses. 17. Herpes zoster and post-herpetic neuralgia. Pain Pract. 2011 Jan-Feb;11(1):88-97. [PubMed] DOI: 10.1111/j.1533-2500.2010.00428.x

11. England J, Wagner T, Kern KU, Roth-Daniek A, Sell A. The capsaicin $8 \%$ patch for peripheral neuropathic pain. $\mathrm{Br} J$ Nurs. 2011;20:926-931. [PubMed] DOI: 10.12968/bjon.2011.20.15.926
12. Garnock-Jones KP, Keating GM. Lidocaine $5 \%$ medicated plaster: a review of its use in postherpetic neuralgia. Drugs. 2009;69:2149-2165. [PubMed] DOI: 10.2165/11203220000000000-00000

13. Backonja M, Wallace MS, Blonsky ER, Cutler BJ, Malan P $\mathrm{Jr}$, Rauck $\mathrm{R}$, et al. NGX-4010, a high-concentration capsaicin patch, for the treatment of postherpetic neuralgia: a randomised, double-blind study. Lancet Neurol. 2008;7:1106-1112. [PubMed] DOI: 10.1016/S14744422(08)70228-X

14. Irving GA, Backonja MM, Dunteman E, Blonsky ER, Vanhove GF, Lu SP, et al. A multicenter, randomized, double-blind, controlled study of NGX-4010, a highconcentration capsaicin patch, for the treatment of postherpetic neuralgia. Pain Med. 2011;12:99-109. [PubMed] DOI: 10.1111/j.1526-4637.2010.01004.x

15. Simpson DM, Brown S, Tobias J; NGX-4010 C107 Study Group. Controlled trial of high-concentration capsaicin patch for treatment of painful HIV neuropathy. Neurology. 2008;70:2305-2313. [PubMed] DOI: 10.1212/01.wnl.0000314647.35825.9c 